\title{
Degree of differentiation in colorectal adenocarcinomas: a multivariate analysis of the influence on survival
}

\author{
T B HALVORSEN, * E SEIM† \\ From the *Department of Pathology, Trondheim Regional and University Hospital, and the $†$ Department of \\ Mathematics and Statistics, AVH, University of Trondheim, Trondheim, Norway
}

SUMMARY Three hundred and sixty eight resected colorectal adenocarcinomas were graded (WHO) retrospectively and the results correlated with estimated length of patient survival. In $30(82 \%)$ of the tumours more than one degree of differentiation was found. Histological grade significantly influenced survival time when other explanatory variables such as tumour site and stage, age, and sex were adjusted for. The results suggested that three degrees of differentiation (well, moderate, and poor) are sufficient for the grading of colorectal carcinomas, and that grading should be based on the predominating degree of differentiation represented in the primary tumour.

The prognosis of patients with colorectal cancer is predicted mainly on the basis of clinicopathological staging and histological grading. ${ }^{1-4}$ The degree of differentiation of the tumour tissue has generally been considered to reflect the grade of malignancy ${ }^{5}$ and is the only histological variable that is used routinely for tumour grading. Colorectal cancers, however, often contain areas with different degrees of differentiation. ${ }^{4-9}$ Unfortunately, no firm guidelines exist as to the grading of such composite tumours, although most pathologists probably are inclined to base their grading on the most poorly differentiated area. ${ }^{4610}$

Little is known about the prognostic importance of the quantitative association between areas of tumour showing different degrees of differentiation. This investigation aimed to study the influence of tumour differentiation on survival in patients with colorectal cancer. Special emphasis was placed on the importance of areas exhibiting different degrees of differentiation in the primary tumour.

\section{Material and methods}

Histological material from 983 patients with colorectal cancer, diagnosed between 1964 and 1978, was reexamined by one of us (TBH) without knowledge of clinical details. " Data on sex, age, tumour site, tumour size and clinical stage were retrieved from the clinical and pathological reports. Tumour was resected in 599 patients, 409 of whom had adenocarcinoma. ${ }^{5}$

Accepted for publication 5 January 1988
Patients who died from postoperative complica- . tions ( 30 cases) were excluded from the study, as were two cases in which histological grading could not be performed, and nine patients above 85 years of age at admission.

The mean ages of the remaining 368 patients were $65.9($ SEM 0.7$)$ for the men and $63.2(0.4)$ years for the women (range 27 to 85 years).

The histological sections were stained with haematoxylin and eosin and saffron. About three sections from each tumour were examined. The deepest infiltrating part of the tumour was represented in at least one of the sections in every case, and in most cases the transitional zone between normal mucosa and the tumour edge was also studied. The rectangular mounted sections measured between about $1 \times 1 \mathrm{~cm}$ to $1.5 \times 3.0 \mathrm{~cm}$.

Histological grading was based on the degree of differentiation defined by the World Health Organisation's expert group on histological typing of intestinal tumours: ${ }^{5}$ well differentiated (low grade malignancy); moderately differentiated (average grade malignancy); and poorly differentiated (high grade malignancy) (fig 1). The presence and extent of areas exhibiting each of these differentiations was scored semiquantitatively for all sections taken from the primary tumour as follows: $0=$ absent; $1=$ present only in small areas; 2 = two or more degrees of differentiation distributed equally throughout the tissue; $3=$ predominance of one type in most areas.

A set of three scores was obtained for the degrees of differentiation in each tumour, and the tumours were 

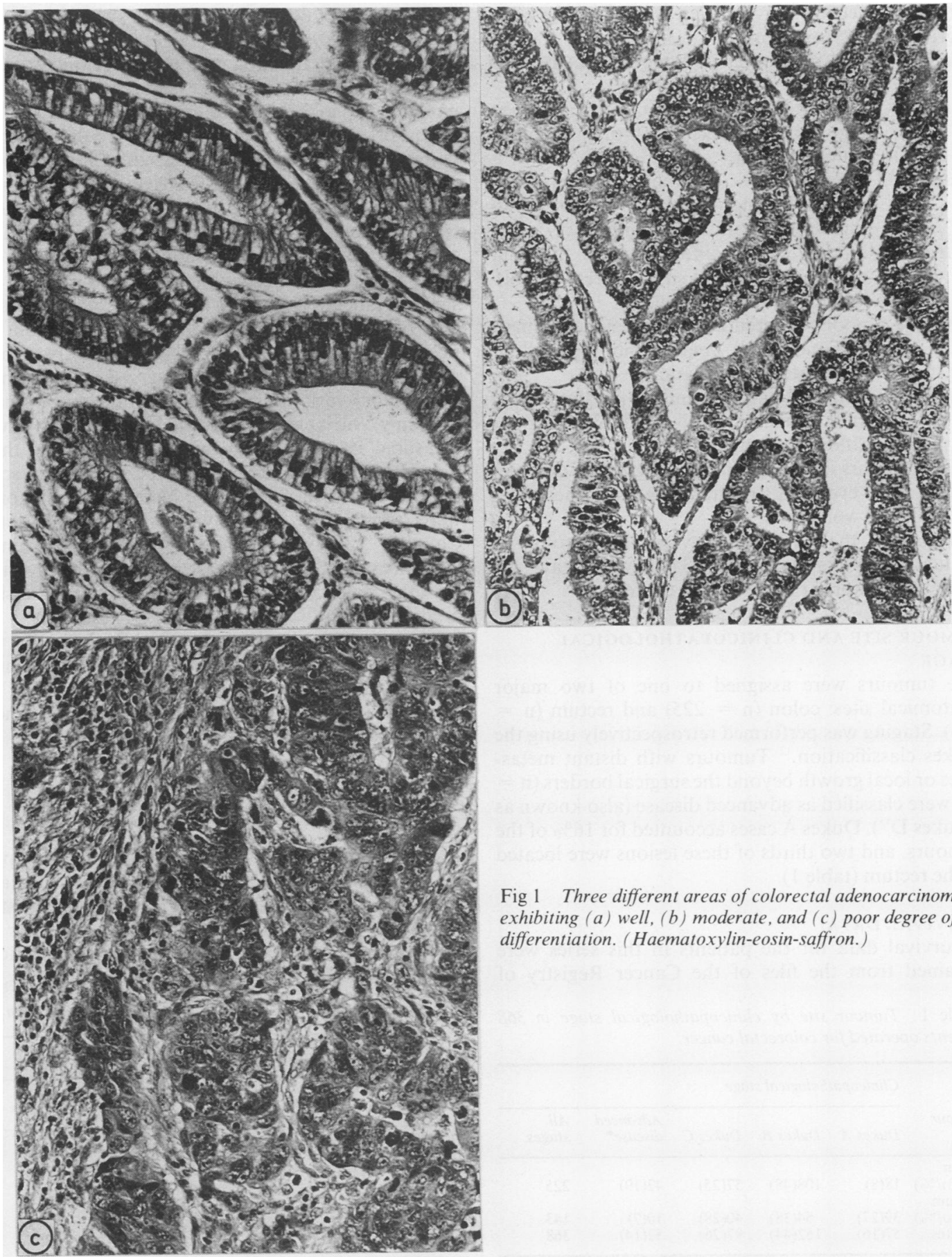

Fig 1 Three different areas of colorectal adenocarcinoma exhibiting (a) well, (b) moderate, and (c) poor degree of differentiation. (Haematoxylin-eosin-saffron.) 
divided into six different histological categories according to the predominant degree of differentiation, taking into account any smaller areas showing other degrees of differentiation.

Category 1 well differentiated tumour present in all areas.

Category 2 well differentiated tumour predominating and smaller areas exhibiting moderate differentiation.

Category 3 moderately differentiated tumour predominating wth smaller areas exhibiting well differentiated glands.

Category 4 moderately differentiated tumour predominating and smaller areas exhibiting poor differentiation.

Category 5 poorly differentiated tumour predominating and small areas exhibiting well or moderate differentiation.

Category 6 well differentiated tumour predominating and smaller areas exhibiting poor differentiation.

For tumours in which different degrees of differentiation were evenly distributed, the assessment was based on the worst area.

To check the reproducibility of the histological evaluation 154 random cases $(38 \%)$ were drawn by computer to appear twice during the review.

\section{TUMOUR SITE AND CLINICOPATHOLOGICAL}

STAGE

The tumours were assigned to one of two major anatomical sites: colon $(n=225)$ and rectum $(n=$ 143). Staging was performed retrospectively using the Dukes classification. ${ }^{12}$ Tumours with distant metastases or local growth beyond the surgical borders $(\mathrm{n}=$ 52) were classified as advanced disease (also known as "Dukes D"). Dukes A cases accounted for $16 \%$ of the tumours, and two thirds of these lesions were located in the rectum (table 1).

SUR VIVAL DATA

Survival data for the patients in this series were obtained from the files of the Cancer Registry of

Table 1 Tumour site by clinicopathological stage in 368 patients operated for colorectal cancer.

\begin{tabular}{llllll}
\hline \multicolumn{5}{c}{ Clinicopathological stage } \\
\cline { 2 - 6 } $\begin{array}{l}\text { Tumour } \\
\text { site }\end{array}$ & Dukes $A$ & Dukes $B$ & Dukes $C$ & $\begin{array}{l}\text { Advanced } \\
\text { disease* }\end{array}$ & $\begin{array}{l}\text { All } \\
\text { stages }\end{array}$ \\
\hline $\begin{array}{c}\text { Colon } \\
(\text { No/\%) }\end{array}$ & $18(8)$ & $108(48)$ & $57(25)$ & $42(19)$ & 225 \\
$\begin{array}{c}\text { Rectum } \\
(\text { No/\%) }\end{array}$ & $39(27)$ & $54(38)$ & $40(28)$ & $10(7)$ & 143 \\
All sites & $57(16)$ & $162(44)$ & $97(26)$ & $52(14)$ & 368 \\
\hline
\end{tabular}

*Denotes disease with distant metastases or local tumour growth beyond surgical margins.
Norway up to the end of September 1986. The causes of death were taken from the death certificates. Death due to colorectal cancer was used as the clinical end point. Cut off was 85 years of age.

The survival function was estimated by the Cox proportional hazards regression analysis, ${ }^{13}$ as implemented in the computer program BMDP2L. ${ }^{14}$ By means of a stepwise selection procedure this program permits the identification of a subset of variables that are significantly related to survival. In addition to histological grade defined by the six categories tumour stage and site, age, and sex were also included as explanatory variables in the model. Each explanatory variable was examined by plots of the $\log$ minus $\log$ survival function ${ }^{15}$ to check the validity of the assumption of proportional effect on the risk function. As tumour site, stage, and histological grade are defined as categories rather than as "observed values", these explanatory variables were coded by means of binary "dummy" variables with the value of 0 or 1 . Age was measured in years. Stage was represented by three binary covariates to circumvent the problem of scoring this four level factor. The histological categories were represented similarly by binary covariates. Category 5 (poorly differentiated areas predominating) was selected as the "baseline grade" with which the other categories were compared in the regression model.

The overall survival time was calculated by the product limit method of Kaplan-Meier as implemented in the computer program BMDP1L. ${ }^{14}$

Cohen's $\kappa$ statistic ${ }^{16}$ was used to test the agreement of the histological evaluations:

$$
\kappa=\frac{p_{o}-p_{e}}{1-p_{e}}
$$

$p_{o}$ is the observed proportion of agreement and $p_{e}$ is the proportion to be expected by chance. Standard error of $\kappa$ was estimated using the formula suggested by Fleiss. ${ }^{17} \mathrm{~A}$ value of $\kappa \geqslant+0.75$ was taken as an index of good agreement beyond chance expectation, and a value of $\kappa \leqslant+0.40$ was regarded as poor. A

Table 2 Clinicopathological stage by histological category

\begin{tabular}{lccccc}
\hline \multirow{5}{*}{$\begin{array}{l}\text { Histo- } \\
\text { logical } \\
\text { category }\end{array}$} & Dukes $A$ & Dukes $B$ & Dukes $C$ & $\begin{array}{l}\text { Advanced } \\
\text { disease }\end{array}$ & $\begin{array}{l}\text { All } \\
\text { stages }\end{array}$ \\
\cline { 2 - 6 } & & & & \\
\hline $1(\mathrm{No} / \%)$ & $6(26)$ & $14(61)$ & $1(4)$ & $2(9)$ & 23 \\
$2(\mathrm{No} / \%)$ & $16(17)$ & $49(52)$ & $22(23)$ & $8(8)$ & 95 \\
$3(\mathrm{No} / \%)$ & $30(18)$ & $70(43)$ & $39(24)$ & $25(15)$ & 164 \\
$4(\mathrm{No} / \%)$ & $1(3)$ & $12(31)$ & $18(46)$ & $8(20)$ & 39 \\
$5(\mathrm{No} / \%)$ & $3(7)$ & $17(39)$ & $16(36)$ & $8(18)$ & 44 \\
$6(\mathrm{No} / \%)$ & $1(33)$ & $0(0)$ & $1(33)$ & $1(33)$ & 3 \\
All & $57(16)$ & $162(44)$ & $97(26)$ & $52(14)$ & 368 \\
\hline
\end{tabular}

Denotes disease with distant spread or local tumour growth beyond the surgical margins. 
Table 3 Regression coefficients with standard errors and $p$ values in proportional hazards analysis.

\begin{tabular}{|c|c|c|c|}
\hline Variable & Regression coefficient (SE) & Exp (coefficient) & $p$ value \\
\hline $\begin{array}{l}\text { Age } \\
\text { Sex: }\end{array}$ & $0.012(0.008)$ & 1.01 & $0 \cdot 12$ \\
\hline $\begin{array}{l}\text { Male } v \text { female } \\
\text { Tumour site: }\end{array}$ & $0 \cdot 190(0 \cdot 161)$ & $1 \cdot 21$ & $0 \cdot 24$ \\
\hline $\begin{array}{l}\text { Colon } v \text { rectum } \\
\text { Stage: }\end{array}$ & $-0 \cdot 776(0 \cdot 163)$ & 0.46 & 0.00 \\
\hline $\begin{array}{l}\text { Dukes B } v \text { Dukes A } \\
\text { Dukes C } v \text { Dukes A } \\
\text { Advanced disease } v \text { Duke A }\end{array}$ & $\begin{array}{l}1 \cdot 189(0 \cdot 332) \\
1 \cdot 714(0 \cdot 339) \\
2 \cdot 419(0 \cdot 358)\end{array}$ & $\begin{array}{r}3 \cdot 28 \\
5 \cdot 55 \\
11 \cdot 23\end{array}$ & $\begin{array}{l}0.00 \\
0.00 \\
0.00\end{array}$ \\
\hline 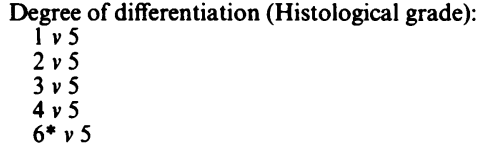 & $\begin{array}{l}-1.645(0.461) \\
-1.550(0.275) \\
-0.807(0.227) \\
-0.800(0.293)\end{array}$ & $\begin{array}{l}0 \cdot 19 \\
0.21 \\
0.45 \\
0.45\end{array}$ & $\begin{array}{l}0.00 \\
0.00 \\
0.00 \\
0.01\end{array}$ \\
\hline
\end{tabular}

*Omitted from the analysis because of few observations $(n=3)$.

value of $\kappa$ between +0.40 and +0.75 was taken as an index of only moderate agreement. ${ }^{18}$

\section{Results}

Areas with different degrees of differentiation were found in $301(82 \%)$ tumours. Well differentiated areas were found in $293(80 \%)$, moderately in $334(91 \%)$, and poorly in $86(23 \%)$.

The overall measure of the intraobserver reproducibility of the histological classification of the 154 random cases into six categories was $\kappa=+0.70$ (SE 0.05).

There was a trend for an increasing proportion of moderately and poorly differentiated areas in advanced stage tumours (table 2). The Cox analysis, however, showed that histological grade represented an additional explanatory factor with independent prognostic influence (table 3 ).

The values of the regression coefficients for the histological categories given in table 3 suggested a

Table 4 Regression of coefficients with standard errors and relative risk with $95 \%$ confidence interval in final model of proportional hazards analysis

\begin{tabular}{|c|c|c|}
\hline Variable & $\begin{array}{l}\text { Regression } \\
\text { coefficient } \\
(S E)\end{array}$ & $\begin{array}{l}\text { Exp } \\
\text { (coefficient) } \\
\text { (95\% } \\
\text { confidence } \\
\text { limits) }\end{array}$ \\
\hline $\begin{array}{l}\text { Tumour site: } \\
\text { Colon } v \text { rectum }\end{array}$ & $-0.813(0 \cdot 160)$ & $0.44(0.32 ; 0.61)$ \\
\hline $\begin{array}{l}\text { Stage: } \\
\text { Dukes B } v \text { Dukes A } \\
\text { Dukes C } v \text { Dukes A } \\
\text { Advanced disease } v \\
\text { Dukes A }\end{array}$ & $\begin{array}{l}1 \cdot 185(0 \cdot 331) \\
1 \cdot 700(0 \cdot 336) \\
2 \cdot 411(0 \cdot 358)\end{array}$ & $\begin{array}{l}3 \cdot 27(1 \cdot 69 ; 6 \cdot 34) \\
5 \cdot 48(2 \cdot 80 ; 10 \cdot 72) \\
11 \cdot 14(5 \cdot 45 ; 22 \cdot 81)\end{array}$ \\
\hline $\begin{array}{l}\text { Tumour differentiation*: } \\
\text { Well } v \text { poor } \\
\text { Moderate } v \text { poor }\end{array}$ & $\begin{array}{l}-1.544(0.262) \\
-0.782(0.219)\end{array}$ & $\begin{array}{l}0 \cdot 21(0 \cdot 13 ; 0 \cdot 36) \\
0 \cdot 46(0 \cdot 29 ; 0 \cdot 71)\end{array}$ \\
\hline
\end{tabular}

* Grading based on the predominating degree represented in the tumour. gradually worsening influence on the prognosis from category 1 onwards, category 5 being associated with the highest risk. The pair of coefficients for categories 3 and 4 were nearly identical, and the difference between the corresponding coefficients for categories 1 and 2 was only $0 \cdot 11$ (NS). Age and sex did not have any significant influence on survival. In the final model, therefore, the histological categories were grouped according to the predominating degree of differentiation represented in the tumours, and age and sex were omitted as explanatory variables.

In the final model (table 4) the estimated difference between the regression coefficients for (predominantly) moderately differentiated tumours and (predominantly) well differentiated tumours was $0 \cdot 76$, which is significantly different from zero $(p=0.02)$.

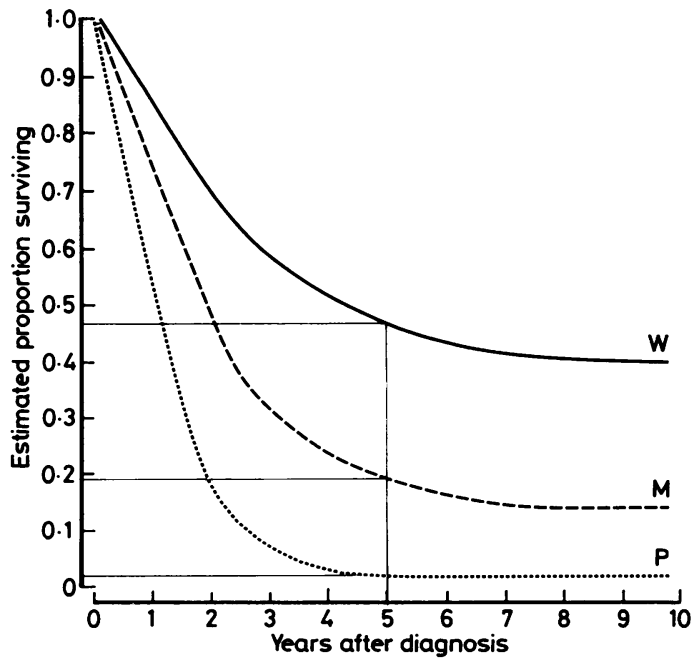

Fig 2 Estimated survival function for patients with well $(W)$, moderately $(M)$, and poorly $(P)$ differentiated rectal tumours. Standardised to Dukes $C$ lesions. Five year survivals indicated. 
The corresponding difference between (predominantly) poorly differentiated and (predominantly) moderately differentiated tumours was 0.78 ( $p$ $<0.01)$. The relative hazard ratio was $\exp (-0.78)=$ 0.46 for tumours classified as moderately differentiated compared with poorly differentiated tumours. The index for the overall reproducibility of this three level grading was $\kappa=+0.80$ (SE 0.05).

Tumour stage was the major prognostic factor, followed by histological grade and tumour site. The risk of death in patients with colonic cancer was estimated to be about one half $(0.44)$ of the risk in those with rectal cancer (table 4).

The estimated overall five year survival in this series was 52.5 (SE 2.7)\%. The influence of the histological grade on the prognosis is shown in fig 2 , which illustrates the estimated survival functions for a selected group of patients with Dukes C rectal tumours.

\section{Discussion}

In colorectal carcinoma the loss of regular arrangement of tumour cells, together with increasing cellular atypia and increasing number of mitoses are among the features which, most pathologists consider, signify a decreasing degree of differentiation and herald a poorer prognosis, ${ }^{1-4}$ or which serve as criteria for further treatment after the histopathological examination of the surgical specimen. ${ }^{19}$ The morphological heterogeneity of colorectal carcinomas, however, is well known..$^{4-9}$ In this study only $18 \%$ of the tumours were monomorphic with regard to histological grade, corroborating the observation by Qualheim and Gall, ${ }^{7}$ who found a consistent histological structure throughout the tumour in $27.7 \%$ of the cases in their series.

The heterogeneity of colorectal cancers and the lack of firm guidelines for the grading of tumours exhibiting areas with different degrees of differentiation may explain' why some authors have found widely varying proportions of histological grades when they compared the results from different laboratories, ${ }^{10}$ and it may partly explain why only slight to moderate interobserver agreement has been observed in reproducibility tests. ${ }^{90}$

As far as tumour grading is concerned, the clone selection concept for tumour spread ${ }^{21}$ would make it logical to perform grading on the basis of "the worst area" represented in the primary tumour, which probably is the principle followed by most pathologists. The design of the present study, however, enabled us to evaluate the usefulness of an alternative principle for turrour grading-namely, grading by the predominating degree of differentiation.

As prognostic factors may be interdependent to a greater or lesser degree, as for instance tumour stage and histological grade in the present study, it is important to consider that such partly interdependent factors may not simply reflect one single biological property. Age, sex, and tumour site are other examples of possible prognostic factors that may be related to each other as well as to tumour stage and histological grade. Although histological grade was the variable of primary interest in our study, we found it appropriate to include other explanatory variables in the regression analysis model. A detailed discussion of the assumptions and limitations of this statistical model, however, is beyond the scope of this paper.

Some authors have commented on the presence of inorderly and apparently poorly differentiated growth at the advancing border of a tumour, and have suggested that such areas should be ignored in the grading of the tumour. ${ }^{4}$ This view is supported by the observations in the present study which have shown that quantitative relations between areas exhibiting different degrees of differentiation may be of prognostic importance. As small areas exhibiting a lower degree of differentiation than the main part of the tumour did not significantly worsen the prognosis estimated on the basis of the predominating grade, we conclude that histological grading in colorectal cancer should be based on the predominating degree of differentiation represented in the primary tumour.

We thank the staff at the Cancer Registry of Norway, Oslo for providing survival data, Mrs Mette Heim for technical assistance, and Mrs Sigrun Ørnsjø for typing the manuscript.

This study was made possible by grants from Kreftfondet ved Regionsykehuset i Trondheim, and financial support from the Norwegian Research Council for Science and the Humanities (Norges Almenvitenskapelige Forskningsråd).

\section{References}

1 Grinnell RS. The grading and prognosis of carcinoma of the colon and rectum. Ann Surg 1939;109:500-33.

2 Godwin JD, Brown CC. Some prognostic factors in survival of patients with cancer of the colon and rectum. J Chron Dis 1975;28:441-54.

3 Chapuis PH, Dent OF, Fisher R, et al. A multivariate analysis of clinical and pathological variables in prognosis after resection of large bowel cancer. Br J Surg 1985;72:698-702.

4 Jass JR, Atkin WS, Cuzik J, et al. The grading of rectal cancer: historical perspectives and a multivariate analysis of 447 cases. Histopathology 1986;10:437-59.

5 World Health Organisation. Histological typing of intestinal tumours. In: International histological classification of tumours, No 15. Geneva: WHO, 1976.

6 Hultbom K.A. Cancer of the eolon and rectum: A clinical and pathological study with special reference to the possibilities of improving the diagnostic methods and the therapeutic results in adenocarcinoma. Acta Chir Scand 1952;172(suppl):62-77.

7 Qualheim RE, Gall EA. Is histological grading of colon carcinoma 
a valid procedure? Archives of Pathology 1963;56:466-72.

8 Smedley $\mathrm{FH}$; Hoile RW, Macfarlane DA. Rectal biopsies: Inaccuracy of histological grading in carcinoma of the rectum. $J R$ Soc Med 1984;77:564-6,

9 Quirke P, Dyson JED, Dixon MF, Bird CC, Joslin CAF. Heterogeneity of colorectal adenocarcinomas evaluated by flow cytometry and histopathology. Br J Cancer 1985;51:99-106.

10 Blenkinsopp WK, Stewart-Brown S, Bleskovsky L, Kearney G, Fielding LP. Histopathology reporting in large bowel cancer. J Clin Pathol 1981;34:509-13:

11 Halvorsen TB. Site distribution of colorectal adenocarcinomas: A retrospective study of 853 tumours. Scand J Gastroenterol 1986;21:973-8.

12 Dukes CE. Cancer of rectum: an analysis of 1000 cases. J Pathol Bacteriol 1940;50:527-39.

13 Cox DR. Regression models and life-tables. $J$ R Statist Soc (B) 1972;34:187-220.

14 Dixon WJ, ed. BMPD statistical software. Berkely, USA: University of California Press, 1983.

15 Kay R. Proportional hazard regression models and the analysis of censored survival data. Appl Statist 1977;26:227-37.

16 Cohen J. A coefficient of agreement for nominal scales. Educational and Psychological Measurement 1960;26:37-46.

17 Fleiss JL. Statistical methods for rates and proportions. 2nd ed. New York: John Wiley \& Sons, 1981.

18 Landis JR, Koch GG. The measurement of observer agreement for categorical data. Biometics 1977;33:159-74.

19 Whiteway J, Nicholls RJ, Morson BC. The role of surgical local excision in the treatment of rectal cancer. Br J Surg 1985;72:694-7.

20 Thomas GDH, Dixon MF, Smeeton NC, Williams NS. Observer variation in the histological grading of rectal carcinoma. J Clin Pathol 1983;36:385-91.

21 Poste G, Fidler IJ. The pathogenesis of cancer metastasis. Nature 1980;283:139-46.

Requests for reprints to: Tore B Halvorsen, Department of Pathology, Trondheim Regional and University Hospital, N7000 Trondheim, Norway. 